\title{
Reduced Vitamin D Levels are Associated with Stroke-Associated Pneumonia in Patients with Acute Ischemic Stroke
}

This article was published in the following Dove Press journal:

Clinical Interventions in Aging

\author{
Gui-Qian Huang ',* \\ Hao-Ran Cheng ${ }^{1, *}$ \\ Yue-Min Wu (iD) \\ Qian-Qian Cheng ${ }^{2}$ \\ Yu-Min Wang (D) ${ }^{3}$ \\ Jia- $\mathrm{Li} \mathrm{Fu}{ }^{3}$ \\ Hui-Xin Zhou ${ }^{3}$ \\ Zhen Wang'
}

'Department of Neurology, The First Affiliated Hospital of Wenzhou Medical University, Wenzhou 325000, Zhejiang, People's Republic of China; ${ }^{2}$ School of Mental Health, Wenzhou Medical University, Wenzhou 325000, Zhejiang, People's Republic of China; ${ }^{3}$ Department of Laboratory Medicine, The First Affiliated Hospital of Wenzhou Medical University, Wenzhou 325000, Zhejiang, People's Republic of China

*These authors contributed equally to this work
Correspondence: Zhen Wang Department of Neurology, The First Affiliated Hospital of Wenzhou Medical University, Wenzhou 325000, Zhejiang, People's Republic of China

Tel +86 577-555780166

Fax +86 577-55578033

Email wangzhen_wenzhou@I63.com
Background and aim: Stroke-associated pneumonia (SAP) is a common complication in patients with acute ischemic stroke (AIS). This study explored the potential relationship between serum vitamin D levels and SAP.

Methods: This study recruited 863 consecutive AIS patients. In-hospital SAP was defined as a complication that occurred after stroke, during hospitalization, that was confirmed radiographically. Serum vitamin D levels were measured within $24 \mathrm{hrs}$ of admission and the patients were divided into vitamin D sufficient ( $>50 \mathrm{nmol} / \mathrm{L})$, insufficient $(25-50 \mathrm{nmol} / \mathrm{L})$, and deficient $(<25 \mathrm{nmol} / \mathrm{L})$ groups.

Results: In this study, $102(11.8 \%)$ patients were diagnosed with SAP. Compared to the patients without SAP, patients with SAP had significantly lower vitamin D levels $(\mathrm{P}=0.023)$. The incidence of SAP was significantly higher in patients with vitamin D deficiency than in those with vitamin D insufficiency or sufficiency $(21.2 \%$ vs $16.2 \% \& 9.5 \%, \mathrm{P}=0.006)$. After adjusting for confounders, vitamin $\mathrm{D}$ deficiency and insufficiency were independently associated with SAP $(\mathrm{OR}=3.034,95 \% \mathrm{CI}=1.207-7.625, \mathrm{P}=0.018$; OR $=1.921,95 \%$ $\mathrm{CI}=1.204-3.066, \mathrm{P}=0.006$, respectively). In multiple-adjusted spline regression, vitamin $\mathrm{D}$ levels showed a linear association with the risk of SAP $(\mathrm{P}<0.001$ for linearity).

Conclusion: Reduced vitamin D is a potential risk factor of in-hospital SAP, which can help clinicians identify high-risk SAP patients.

Keywords: acute ischemic stroke, stroke-associated pneumonia, vitamin D

\section{Introduction}

Stroke patients are more likely to have pneumonia during hospitalization, and the prevalence of stroke-associated pneumonia (SAP) ranges from 7.1 to $31.3 \% .^{1-5}$ Studies have confirmed that SAP is independently associated with early mortality, prolonged hospitalization, and poor outcomes among stroke patients. ${ }^{1,3,6,7}$ To improve the prognosis of stroke patients, it is necessary to identify risk factors for SAP early, to enable preventive interventions and treatment.

Vitamin D is a neurosteroid hormone that affects various diseases, including stroke, cardiovascular disease, and multiple sclerosis. ${ }^{8-11}$ Clinical studies show that low vitamin D levels are common in stroke patients due to reduced vitamin D intake, a lack of outdoor exercise, and decreased physiological synthesis. ${ }^{8,12-14}$ Furthermore, vitamin D has anti-inflammatory properties and low vitamin D levels may lead to increased inflammatory activity. ${ }^{15,16}$ Therefore, we hypothesized that a reduction in 
vitamin D levels might be associated with the occurrence of pneumonia after acute stroke.

Given that low vitamin D levels are common in stroke patients, we aimed to explore the association between vitamin D levels and SAP in patients with acute ischemic stroke (AIS).

\section{Methods}

\section{Study Design}

We enrolled patients form a retrospective clinical database that included consecutive patients who were admitted to the Department of Neurology, First Affiliated Hospital of Wenzhou Medical University, within 24 hrs after the onset of ischemic stroke between October 2017 and October 2018.

This retrospective study was approved by the Ethics Committee of the First Affiliated Hospital of Wenzhou Medical University. Because this study was retrospective and all included data were anonymous, the requirement that patients give informed consent was waived.

\section{Inclusion and Exclusion Criteria}

All patients with suspected AIS were confirmed by cranial computed tomography (CT) or magnetic resonance imaging (MRI) within $24 \mathrm{hrs}$ of admission. The exclusion criteria were as follows: (i) diagnosed with transient ischemic attack; (ii) active infection or pyrexia within 2 weeks before admission; (iii) preventive antibiotic therapy; (iv) history of any other central nervous system disease, such as brain trauma, cerebral hemorrhage, hydrocephalus, and Parkinson's disease; (v) severe hepatic disease (serum transaminase concentration exceeding twice the upper limit of the reference range within 6 months or persistent hyperbilirubinemia); (vi) severe renal disease [glomerular filtration rate $(\mathrm{GFR})<60 \mathrm{~mL} \min ^{-1} 1.73 \mathrm{~m}^{-2}$ ]; (vii) osteoporosis or taking vitamin D supplementation before stroke onset; and (viii) lack of complete medical and laboratory records. Ultimately, 863 patients were enrolled in this study and their data were analyzed (Figure 1).

\section{Data Collection}

The patients' demographic data, including age and gender, were collected from their medical records. Baseline clinical parameters were obtained, including stroke subtype (according the TOAST criteria), ${ }^{17}$ previous stroke, dysphagia, current cigarette smoking, current alcohol consumption, and arterial blood pressure. Pre-existing comorbidities included hypertension, diabetes, coronary heart disease, and chronic obstructive pulmonary disease

802 patients were excluded

1) Transient ischemic attack $(\mathrm{n}=65)$

2) Active infection or pyrexia within 2 weeks before admission $(n=61)$

3) Preventive antibiotic therapy $(n=153)$

4) History of any other central nervous system disease $(n=80)$

5) Severe hepatic or renal diseases $(n=103)$

6) Osteoporosis or taking vitamin D supplementation before stroke onset $(\mathrm{n}=79)$

7) Missing complete medical and laboratory records $(\mathrm{n}=261)$

Total 863 patients were included

Figure I Study flow diagram. AIS, acute ischemic stroke. 
(COPD). The baseline laboratory examinations, including vitamin D, fasting blood glucose, high-density lipoprotein cholesterol (HDL-C), low-density lipoprotein cholesterol (LDL-C), serum creatinine (SCr), blood urea nitrogen (BUN), GFR, platelets, leukocytes, and total cholesterol, were obtained within $24 \mathrm{hrs}$ of admission. The stroke severity was assessed by well-trained neurologists using the National Institutes of Health Stroke Scale (NIHSS) score within 24 hrs of hospital admission.

\section{Vitamin D Tests}

Blood samples were obtained within 24 hrs of admission. Vitamin D status was evaluated by measuring 25hydroxyvitamin $\mathrm{D}[25(\mathrm{OH}) \mathrm{D}]$, which is the main active form of vitamin $\mathrm{D}$ and is a good indicator of the total vitamin D level. The serum $25(\mathrm{OH}) \mathrm{D}$ levels were measured using a competitive electrochemiluminescence protein binding assay in our hospital laboratory. According to the previous studies, ${ }^{18,19}$ the patients were divided into the following three clinically relevant groups based on the 25 $(\mathrm{OH}) \mathrm{D}$ concentrations: vitamin D sufficient $(>50 \mathrm{nmol} / \mathrm{L})$, insufficient $(25-50 \mathrm{n} \mathrm{nmol} / \mathrm{L})$, and deficient $(<25 \mathrm{nmol} / \mathrm{L})$ groups.

\section{Outcome Measures}

The diagnosis of in-hospital SAP was based on clinical and laboratory examinations according to the modified Centers for Disease Control and Prevention criteria for hospital-acquired pneumonia. ${ }^{20}$ Patients suspected of having pneumonia based on chest X-rays and clinical symptoms were diagnosed and confirmed by chest CT and sputum cultures. ${ }^{21}$ SAP was diagnosed by two experienced neurologists blinded to the results of the clinical and laboratory examinations. Only hospital-acquired pneumonia was recorded; pneumonia before stroke and community-acquired pneumonia were not considered in this study.

\section{Statistical Analysis}

Continuous variables are presented as the mean \pm standard deviation or median and interquartile range (IQR) according to the normal or non-normal distribution of data determined by the Kolmogorov-Smirnov test. The significance of differences in continuous variables in the patient subgroups with and without SAP was analyzed with Student's $t$-test or the Mann-Whitney $U$-test, as appropriate. Categorical variables were described as relative frequencies and percentages and two groups were compared with the chi-square test. Statistical comparisons among different vitamin D groups were assessed with the Kruskal-Wallis test or one-way analysis of variance (ANOVA) for continuous variables and Pearson's chi-square test or Fisher's exact test for categorical variables. Binary univariate logistic regression analysis was used to find confounding variables that were associated with SAP. Then, all confounding variables (defined as $\mathrm{P}<0.1$ ) were included in multivariate logistic regression models to adjust for potential confounding and assess any independent predictors of SAP. An adjusted spline regression model was computed to provide more precise estimates and determine the shape of the associations between serum vitamin $\mathrm{D}$ as a continuous variable and the risk of SAP, ${ }^{22,23}$ fitting a restricted cubic spline function with four knots (5th, 35th, 65th, and 95th percentiles). In this study, two-tailed P-values $<0.05$ were considered statistically significant. All statistical analyses were performed using R for Windows (version 3.4.1; http://www. r-project.org/) and SAS statistical software, version 9.2 (SAS Institute, Cary, NC, USA).

\section{Results}

\section{Baseline Characteristics of the Patients with and Without SAP}

A total of 863 patients were eligible in the study [551 males (63.9\%), 312 females (36.1\%); mean age $66.3 \pm$ 11.4 years; Figure 1]. Of these, $102(11.8 \%)$ patients were diagnosed with in-hospital SAP. The baseline characteristics of the patients with and without SAP are presented in Table 1. Compared to patients without SAP, those with SAP were more likely to be older, cigarette smokers, and had higher baseline NIHSS scores, BUN and leukocyte levels, and lower GFR levels. The median (IQR) values of vitamin D levels in non-SAP and SAP patients were 61.0 (47.7-77.0) and 55.2 (38.9-71.2), respectively. Compared to patients without SAP, those with SAP had significantly lower vitamin $\mathrm{D}$ levels $(\mathrm{P}=0.023)$. Meanwhile, the incidence of dysphagia and hypertension was higher in patients with SAP.

\section{Baseline Characteristics of All Patients According to Vitamin D Status}

Table 2 summarized the basic and laboratory characteristics of the AIS patients stratified by vitamin D status. The incidence of SAP was significantly higher in patients with vitamin D deficiency $(<25 \mathrm{nmol} / \mathrm{L})$ than in those with vitamin D insufficiency or sufficiency $(21.2 \%$ vs $16.2 \%$ \& $9.5 \%$, respectively, $\mathrm{P}=0.006$, Table 2 ). Interestingly, the 
Table I Differences of the Baseline Characteristics in AIS Patients with and Without SAP

\begin{tabular}{|c|c|c|c|}
\hline Variables & $\begin{array}{l}\text { Non-SAP } \\
(n=761)\end{array}$ & $\begin{array}{l}\text { SAP } \\
(n=102)\end{array}$ & P-value* \\
\hline $\begin{array}{l}\text { Demographic parameters } \\
\text { Age (years) } \\
\text { Male, } \mathrm{n}(\%)\end{array}$ & $\begin{array}{l}65.7 \pm 11.5 \\
486(63.9 \%)\end{array}$ & $\begin{array}{l}70.2 \pm 10.1 \\
65(63.7 \%)\end{array}$ & $\begin{array}{l}<0.001 \\
0.978\end{array}$ \\
\hline $\begin{array}{l}\text { Clinical parameters } \\
\text { Stroke subtype } \\
\text { Large-vessel disease } \\
\text { Cardioembolism } \\
\text { Lacunar } \\
\text { Other } \\
\text { Unknown } \\
\text { NHISS score, median (IQR) } \\
\text { Dysphagia, n (\%) } \\
\text { Current smoking, n (\%) } \\
\text { Current drinking, n (\%) } \\
\text { SBP (mmHg) } \\
\text { DBP (mmHg) } \\
\text { History of stroke, n (\%) }\end{array}$ & $\begin{array}{l}600(78.8 \%) \\
96(12.6 \%) \\
50(6.6 \%) \\
7(0.9 \%) \\
8(1.1 \%) \\
3.0(1.0-5.0) \\
91(12.0 \%) \\
319(41.9 \%) \\
282(37.1 \%) \\
152.5 \pm 24.2 \\
83.3 \pm 13.9 \\
105(13.8 \%)\end{array}$ & $\begin{array}{l}77(75.5 \%) \\
20(19.6 \%) \\
4(3.9 \%) \\
0 \\
1(1.0 \%) \\
5.0(3.0-8.0) \\
25(24.5 \%) \\
55(53.9 \%) \\
44(43.1 \%) \\
153.4 \pm 23.1 \\
85.4 \pm 13.5 \\
18(17.6 \%)\end{array}$ & $\begin{array}{l}<0.001 \\
<0.001 \\
0.022 \\
0.234 \\
0.712 \\
0.156 \\
0.296\end{array}$ \\
\hline $\begin{array}{l}\text { Pre-existing comorbidities } \\
\text { Hypertension, n (\%) } \\
\text { Diabetes, n (\%) } \\
\text { Coronary heart disease, } \\
\text { n (\%) } \\
\text { COPD, n (\%) }\end{array}$ & $\begin{array}{l}628(82.5 \%) \\
369(48.5 \%) \\
10(1.3 \%) \\
9(1.2 \%)\end{array}$ & $\begin{array}{l}94(92.2 \%) \\
46(45.1 \%) \\
4(3.9 \%) \\
0\end{array}$ & $\begin{array}{l}0.013 \\
0.520 \\
0.050 \\
\\
0.270\end{array}$ \\
\hline $\begin{array}{l}\text { Laboratory parameters } \\
\text { Vitamin } D(\mathrm{nmol} / \mathrm{L})\end{array}$ & $\begin{array}{l}61.0 \\
(47.7-77.0)\end{array}$ & $\begin{array}{l}55.2 \\
(38.9-71.2)\end{array}$ & 0.023 \\
\hline Fast blood glucose (mmol/L) & $6.5 \pm 2.5$ & $6.6 \pm 2.4$ & 0.777 \\
\hline $\begin{array}{l}\mathrm{HDL}-\mathrm{C}(\mathrm{mmol} / \mathrm{L}) \\
\mathrm{LDL}-\mathrm{C}(\mathrm{mmol} / \mathrm{L})\end{array}$ & $\begin{array}{l}1.0 \pm 0.2 \\
2.7 \pm 1.0\end{array}$ & $\begin{array}{l}1.0 \pm 0.3 \\
2.6 \pm 1.0\end{array}$ & $\begin{array}{l}0.989 \\
0.598\end{array}$ \\
\hline $\mathrm{SCr}(\mu \mathrm{mol} / \mathrm{L})$ & $\begin{array}{l}71.0 \\
(59.0-85.0)\end{array}$ & $\begin{array}{l}70.0 \\
(58.0-83.0)\end{array}$ & 0.763 \\
\hline BUN (mmol/L) & $4.9(4.0-5.9)$ & $5.2(4.1-6.7)$ & 0.038 \\
\hline GFR & $\begin{array}{l}91.1 \\
(74.9-102.3)\end{array}$ & $\begin{array}{l}87.0 \\
(74.2-95.5)\end{array}$ & 0.047 \\
\hline $\begin{array}{l}\text { Leukocyte }\left(\times 10^{9} / \mathrm{L}\right) \\
\text { Platelet }\left(\times 10^{9} / \mathrm{L}\right)\end{array}$ & $\begin{array}{l}6.9 \pm 2.2 \\
219.0 \\
(183.0-257.0)\end{array}$ & $\begin{array}{l}8.8 \pm 3.5 \\
215.0 \\
(173.0-255.0)\end{array}$ & $\begin{array}{l}<0.001 \\
0.465\end{array}$ \\
\hline Total cholesterol (mmol/L) & $4.7 \pm 1.3$ & $4.5 \pm 1.2$ & 0.111 \\
\hline
\end{tabular}

Notes: *Continuous variables were compared between the groups by the Student's $t$-test or the Mann-Whitney test. The chi-square test was used for categorical variables. Abbreviations: BUN, blood urea nitrogen; COPD, Chronic obstructive pulmonary disease; DBP, diastolic blood pressure; GFR, glomerular filtration rate; HDL-C, high density lipoprotein cholesterol; LDL-C, low density lipoprotein cholesterol; NIHSS, National Institutes of Health Stroke Scale; SAP, stroke-associated pneumonia; SBP, systolic blood pressure; SCr, serum creatinine concentration.

incidence of diabetes increased as the vitamin D levels decreased $(\mathrm{P}<0.001)$. Significant differences were also observed for gender, coronary heart disease, HDL-C, and $\mathrm{SCr}$ among patients with different vitamin D status. Otherwise, most characteristics of the patients with low and high vitamin D levels were similar.

\section{Association Between the Serum Vitamin $D$ and SAP}

For the data on the stroke patients, SAP occurrence was taken as the dependent variable and vitamin D sufficiency was taken as a reference in the unadjusted and multivariate-adjusted logistic regression models (Table 3). In the unadjusted logistic regression model (univariate analysis), the odds ratio of SAP increased with decreasing serum vitamin D levels $[1.850(95 \% \mathrm{CI}=1.192-2.872)$ and $2.567(95 \% \mathrm{CI}=1.066-6.182, \mathrm{P}=0.035)]$. The test for trend was significant $(\mathrm{P}=0.0015)$. Age, baseline NIHSS score, GFR levels, hypertension, current smoking, and dysphagia were significantly associated with the risk of $\mathrm{SAP}$ in the univariate analyses (all $\mathrm{P}<0.1$ ). After adjusting for conventional and significant confounders, including age, GFR levels, gender, diabetes mellitus, hypertension, current smoking, baseline NIHSS score and dysphagia, vitamin D deficiency $(<25 \mathrm{nmol} / \mathrm{L})$ was independently associated with the incidence of SAP (model 1: $\mathrm{OR}=2.926,95 \% \mathrm{CI}=1.196-7.159, \mathrm{P}=0.019$; model 2: $\mathrm{OR}=3.293,95 \% \mathrm{CI}=1.318-8.229, \mathrm{P}=0.011$; model 3 : $\mathrm{OR}=2.997,95 \% \mathrm{CI}=1.185-7.584, \mathrm{P}=0.020)$. Vitamin D insufficiency $(25-50 \mathrm{nmol} / \mathrm{L})$ was also independently associated with a lower risk of SAP (model 1: OR $=1.842$, 95\% CI $=1.175-2.889, \mathrm{P}=0.008$; model 2: $\mathrm{OR}=1.935$, $95 \% \mathrm{CI}=1.222-064, \mathrm{P}=0.005$; model $3: \mathrm{OR}=1.963$, $95 \% \mathrm{CI}=1.228-3.136, \mathrm{P}=0.005)$. The adjusted $\mathrm{P}$-values for trend were $0.0011,0.0005$, and 0.0010 in models 1,2 , and 3 , respectively.

Furthermore, the multiple-adjusted cubic spline regressions confirmed the association between SAP risk and serum vitamin D levels. Within the range of vitamin $\mathrm{D}$ less than $50 \mathrm{nmol} / \mathrm{L}$, the spline regression showed a linear relation between an increased risk of SAP and continuously reduced serum vitamin $\mathrm{D}(\mathrm{P}<0.001$ for linearity; Figure 2).

\section{Discussion}

To our knowledge, this is the first study to investigate the association between vitamin $\mathrm{D}$ levels and the development of pneumonia after AIS. We found that vitamin D deficiency and insufficiency at admission were associated with a high risk of in-hospital SAP, and the risk of SAP increased as the vitamin $\mathrm{D}$ levels decreased. Therefore, our results indicated that low vitamin D status could be a reliable risk factor of SAP. 
Table 2 Baseline Characteristics of Patients with Acute Ischemic Stroke According to Different Vitamin D Status

\begin{tabular}{|c|c|c|c|c|c|}
\hline \multirow[t]{2}{*}{ Variables } & \multirow[t]{2}{*}{ All Patients } & \multicolumn{4}{|l|}{ Vitamin D Status } \\
\hline & & $\begin{array}{l}\text { Vitamin } \\
\text { D Deficiency } \\
(n=33)\end{array}$ & $\begin{array}{l}\text { Vitamin } \\
\text { D Insufficiency } \\
(\mathrm{n}=\mathbf{2 4 0})\end{array}$ & $\begin{array}{l}\text { Vitamin } \\
\text { D Sufficiency } \\
(n=590)\end{array}$ & P-value* \\
\hline SAP, n (\%) & $102(11.8 \%)$ & 7 (21.2\%) & 39 (16.2\%) & $56(9.5 \%)$ & 0.006 \\
\hline $\begin{array}{l}\text { Demographic parameters } \\
\text { Age (years) } \\
\text { Gender } \\
\text { Male, } n(\%) \\
\text { Female, } \mathrm{n}(\%)\end{array}$ & $\begin{array}{l}66.2 \pm 11.4 \\
551(63.8 \%) \\
312(36.2 \%)\end{array}$ & $\begin{array}{l}63.2 \pm 12.1 \\
22(66.7 \%) \\
I I(33.3 \%)\end{array}$ & $\begin{array}{l}66.9 \pm 12.7 \\
131(54.6 \%) \\
109(45.4 \%)\end{array}$ & $\begin{array}{l}66.1 \pm 10.8 \\
398(67.5 \%) \\
192(32.5 \%)\end{array}$ & $\begin{array}{l}0.212 \\
0.002\end{array}$ \\
\hline $\begin{array}{l}\text { Clinical parameters } \\
\text { Stroke subtype } \\
\text { Large-vessel disease } \\
\text { Cardioembolism } \\
\text { Lacunar } \\
\text { Other } \\
\text { Unknown } \\
\text { NHISS score, median (IQR) } \\
\text { Thrombolysis, n (\%) } \\
\text { Dysphagia, n (\%) } \\
\text { Current smoking, n (\%) } \\
\text { Current drinking, n (\%) } \\
\text { SBP (mmHg) } \\
\text { DBP (mmHg) } \\
\text { History of stroke, n (\%) }\end{array}$ & $\begin{array}{l}677(78.4 \%) \\
116(13.4 \%) \\
54(6.3 \%) \\
7(0.8 \%) \\
9(1.0 \%) \\
3.0(1.0-6.0) \\
32(3.7 \%) \\
116(13.4 \%) \\
374(43.3 \%) \\
326(37.8 \%) \\
152.6 \pm 24.1 \\
83.5 \pm 13.8 \\
123(14.3 \%)\end{array}$ & $\begin{array}{l}29(87.9 \%) \\
2(6.1 \%) \\
2(6.1 \%) \\
0 \\
0 \\
3.0(1.0-7.0) \\
1(3.0 \%) \\
8(24.2 \%) \\
16(48.5 \%) \\
14(42.4 \%) \\
154.1 \pm 27.0 \\
86.1 \pm 12.7 \\
5(15.2 \%)\end{array}$ & $\begin{array}{l}188(78.3 \%) \\
35(14.6 \%) \\
11(4.6 \%) \\
4(1.7 \%) \\
2(0.8 \%) \\
3.0(1.0-5.75) \\
8(3.3 \%) \\
36(15.0 \%) \\
117(48.8 \%) \\
98(40.8 \%) \\
154.1 \pm 23.5 \\
83.7 \pm 13.9 \\
45(18.8 \%)\end{array}$ & $\begin{array}{l}460(78.0 \%) \\
79(13.4 \%) \\
41(6.9 \%) \\
3(0.5 \%) \\
7(1.2 \%) \\
3.0(1.0-6.0) \\
23(3.9 \%) \\
72(12.2 \%) \\
241(40.8 \%) \\
214(36.3 \%) \\
151.9 \pm 24.2 \\
83.3 \pm 13.9 \\
73(12.4 \%)\end{array}$ & $\begin{array}{l} \\
\\
0.781 \\
0.906 \\
0.101 \\
0.095 \\
0.401 \\
0.446 \\
0.505 \\
0.058\end{array}$ \\
\hline $\begin{array}{l}\text { Pre-existing comorbidities } \\
\text { Hypertension, n (\%) } \\
\text { Diabetes, n (\%) } \\
\text { Coronary heart disease, n (\%) } \\
\text { COPD, n (\%) }\end{array}$ & $\begin{array}{l}722(83.7 \%) \\
415(48.1 \%) \\
14(1.6 \%) \\
9(1.0 \%)\end{array}$ & $\begin{array}{l}25(75.8 \%) \\
19(57.6 \%) \\
2(6.1 \%) \\
1(3.0 \%)\end{array}$ & $\begin{array}{l}192(80.0 \%) \\
138(57.5 \%) \\
6(2.5 \%) \\
3(1.2 \%)\end{array}$ & $\begin{array}{l}505(85.6 \%) \\
258(43.7 \%) \\
6(1.0 \%) \\
5(0.8 \%)\end{array}$ & $\begin{array}{l}0.065 \\
<0.001 \\
0.037 \\
0.454\end{array}$ \\
\hline $\begin{array}{l}\text { Laboratory parameters } \\
\text { Fast blood glucose }(\mathrm{mmol} / \mathrm{L}) \\
\text { HDL-C }(\mathrm{mmol} / \mathrm{L}) \\
\text { LDL-C }(\mathrm{mmol} / \mathrm{L}) \\
\mathrm{SCr}(\mu \mathrm{mol} / \mathrm{L}) \\
\text { BUN }(\mathrm{mmol} / \mathrm{L}) \\
\text { GFR } \\
\text { Leukocyte }\left(\times 10^{9} / \mathrm{L}\right) \\
\text { Platelet }\left(\times 10^{9} / \mathrm{L}\right) \\
\text { Total cholesterol }(\mathrm{mmol} / \mathrm{L})\end{array}$ & $\begin{array}{l}6.5 \pm 2.5 \\
1.0 \pm 0.2 \\
2.7 \pm 1.0 \\
71.0(59.0-85.0) \\
4.9(4.0-6.0) \\
90.5(74.7-101.1) \\
7.2 \pm 2.4 \\
218.0(181.0-257.0) \\
4.7 \pm 1.3\end{array}$ & $\begin{array}{l}6.7 \pm 2.6 \\
0.9 \pm 0.3 \\
2.9 \pm 1.3 \\
69.0(57.0-101.0) \\
4.7(4.0-7.1) \\
87.2(67.8-112.4) \\
7.6 \pm 3.2 \\
217.0(188.0-259.0) \\
5.0 \pm 1.7\end{array}$ & $\begin{array}{l}6.8 \pm 2.5 \\
1.0 \pm 0.3 \\
2.7 \pm 0.9 \\
67.0(55.0-81.0) \\
4.8(3.8-6.0) \\
90.5(75.3-100.6) \\
7.3 \pm 2.6 \\
231.0(186.0-264.0) \\
4.7 \pm 1.2\end{array}$ & $\begin{array}{l}6.4 \pm 2.5 \\
1.0 \pm 0.2 \\
2.7 \pm 1.0 \\
71.0(61.0-85.0) \\
5.0(4.1-6.0) \\
90.7(75.1-101.1) \\
7.1 \pm 2.3 \\
215.0(181.0-255.0) \\
4.7 \pm 1.2\end{array}$ & $\begin{array}{l}0.122 \\
0.016 \\
0.252 \\
0.013 \\
0.445 \\
0.870 \\
0.191 \\
0.148 \\
0.545\end{array}$ \\
\hline
\end{tabular}

Notes: *Continuous variables were compared between the groups by the Kruskal-Wallis test or one-way analysis of variance (ANOVA). The Pearson's chi-square test or Fisher's exact test was used for categorical variables.

Abbreviations: BUN, blood urea nitrogen; COPD, Chronic obstructive pulmonary disease; DBP, diastolic blood pressure; GFR, glomerular filtration rate; HDL-C, high density lipoprotein cholesterol; LDL-C, low density lipoprotein cholesterol; NIHSS, National Institutes of Health Stroke Scale; SAP, stroke-associated pneumonia; SBP, systolic blood pressure; SCr, serum creatinine concentration.

In this study, $11.8 \%$ of the patients were diagnosed with pneumonia after acute stroke during hospitalization, which is consistent with previous findings. ${ }^{3,24-26}$ We found that age and the severity of stoke (NIHSS score) affected the risk of SAP, and these were identified as risk factors for SAP in other population-based studies. ${ }^{27,28}$ Moreover, in our study, $24.5 \%$ of the patients with SAP developed dysphagia, which was significantly increased compared to 
Table 3 Multivariate Adjusted Odds Ratios for the Association Between Vitamin D Levels and SAP

\begin{tabular}{|c|c|c|c|c|}
\hline & \multicolumn{3}{|l|}{ OR $(95 \% \mathrm{Cl})^{a}$} & \multirow{2}{*}{$\begin{array}{l}\text { P-value for } \\
\text { Trend }\end{array}$} \\
\hline & $\begin{array}{l}\text { Vitamin D Deficiency (< } 25 \\
\mathrm{nmol} / \mathrm{L})\end{array}$ & $\begin{array}{l}\text { Vitamin D Insufficiency (25-50 } \\
\mathrm{nmol} / \mathrm{L})\end{array}$ & $\begin{array}{l}\text { Vitamin D Sufficiency (> } 50 \\
\mathrm{nmol} / \mathrm{L})\end{array}$ & \\
\hline $\begin{array}{l}\text { Unadjusted } \\
\text { P-value }\end{array}$ & $\begin{array}{l}2.567(1.066-6.182) \\
0.035\end{array}$ & $\begin{array}{l}1.850(1.192-2.872) \\
0.006\end{array}$ & Reference & 0.0015 \\
\hline $\begin{array}{l}\text { Model I* } \\
\text { P-value }\end{array}$ & $\begin{array}{l}2.926(1.196-7.159) \\
0.019\end{array}$ & $\begin{array}{l}1.842(1.175-2.889) \\
0.008\end{array}$ & Reference & 0.0011 \\
\hline $\begin{array}{l}\text { Model } 2^{\dagger} \\
\text { P-value }\end{array}$ & $\begin{array}{l}3.293(1.318-8.229) \\
0.011\end{array}$ & $\begin{array}{l}1.935(1.222-3.064) \\
0.005\end{array}$ & Reference & 0.0005 \\
\hline $\begin{array}{r}\text { Model } 3^{*} \\
\text { P-value }\end{array}$ & $\begin{array}{l}2.997(1.185-7.584) \\
0.020\end{array}$ & $\begin{array}{l}1.963(1.228-3.136) \\
0.005\end{array}$ & Reference & 0.0010 \\
\hline
\end{tabular}

Notes: ${ }^{a}$ Reference OR (I.000) is the Vitamin D sufficiency for SAP. *Model I: adjusted for age, sex; ${ }^{\dagger}$ Model 2: adjusted for covariates from Model I and further adjusted for diabetes mellitus, hypertension and current smoking; ${ }^{*}$ Model 3: adjusted for covariates from Model 2 and further adjusted for baseline NIHSS scores, dysphagia and glomerular filtration rate.

Abbreviations: OR, odds radio; $\mathrm{Cl}$, confidence level; SAP, stroke-associated pneumonia.

those without SAP. Adjusted logistic regression analysis showed that the presence of dysphagia was associated with the risk of SAP $(\mathrm{OR}=1.855,95 \% \mathrm{CI}=1.049-3.278)$. Currently, only a few published studies have explored the effect of dysphagia in stroke patients. ${ }^{29-31}$ Our findings are in accordance with a study investigated by Martino et $\mathrm{al}^{32}$ who found that dysphagic patients have up to an 11-fold increased risk of SAP. Other recent studies have reported the same results. ${ }^{33,34}$ Furthermore, consistent with many studies, we found that hypertension and current smoking were associated with pneumonia after stroke. ${ }^{3,5,35}$

In the previous studies, several biological indicators had been described as promising biomarkers related to SAP. A Korean group found that AIS patients with higher neutrophil-to-lymphocyte ratios were more likely to catch SAP. $^{26}$ Many observational clinical research found that procalcitonin was useful in the early diagnosis of SAP. $^{36-38}$ Another study found that salivary substance P (SP) levels may be a biomarker to predict SAP because AIS patients with a low frequency of spontaneous swallowing had low salivary SP levels. ${ }^{39}$ Recently, ZapataArriaza et al suggested that pro-adrenomedullin predicted SAP and the combination of serum amyloid A protein/ soluble urokinase-type plasminogen activator receptor could improve its predictive value. ${ }^{40}$ Compared with the above biomarkers, vitamin $\mathrm{D}$ is an original biomarker that is routinely tested clinically.

In this study, the total prevalence of vitamin D deficiency and insufficiency was $31.6 \%$. A database of 41,504 patients from the USA showed that the prevalence of vitamin D deficiency $(\leq 30 \mathrm{ng} / \mathrm{mL})$ was $63.6 \% .{ }^{41}$ In another study in Kampala, Uganda, where the sunshine is adequate, the prevalence was only $15 \% .{ }^{42}$ Thus, the various incidence of low vitamin D levels may be the result of different methods for measuring vitamin $\mathrm{D}$ and different durations of sunlight exposure. Furthermore, we found that the OR of the vitamin D deficiency group was higher than that of the vitamin D insufficiency group, which indicated that the vitamin D level was closely linked to the development of SAP. Therefore, we used restricted cubic spline regression to explore the relation between serum vitamin $\mathrm{D}$ as a continuous parameter and the risk of SAP. Consequently, the restricted cubic spline curve confirmed a linear relation between an elevated SAP risk and continuously decreasing vitamin D levels.

To our knowledge, no other studies have explored the association between vitamin D and SAP. However, many studies have investigated the associations between vitamin $\mathrm{D}$ and respiratory diseases. A recent study found that vitamin D status was inversely associated with the risk of community-acquired pneumonia in community-living adults. ${ }^{43}$ However, a cross-sectional analysis in the Netherlands Epidemiology of Obesity study found that vitamin D concentrations were not associated with lung function or airway inflammation in 6671 people in the general population. ${ }^{44}$ It's worth noting that our participants were the patients who suffered from acute stroke and were vulnerable to infection. In addition, in a murine model of intratracheal lipopolysaccharide challenge, Dancer et al found that vitamin D deficiency may lead to exaggerated 


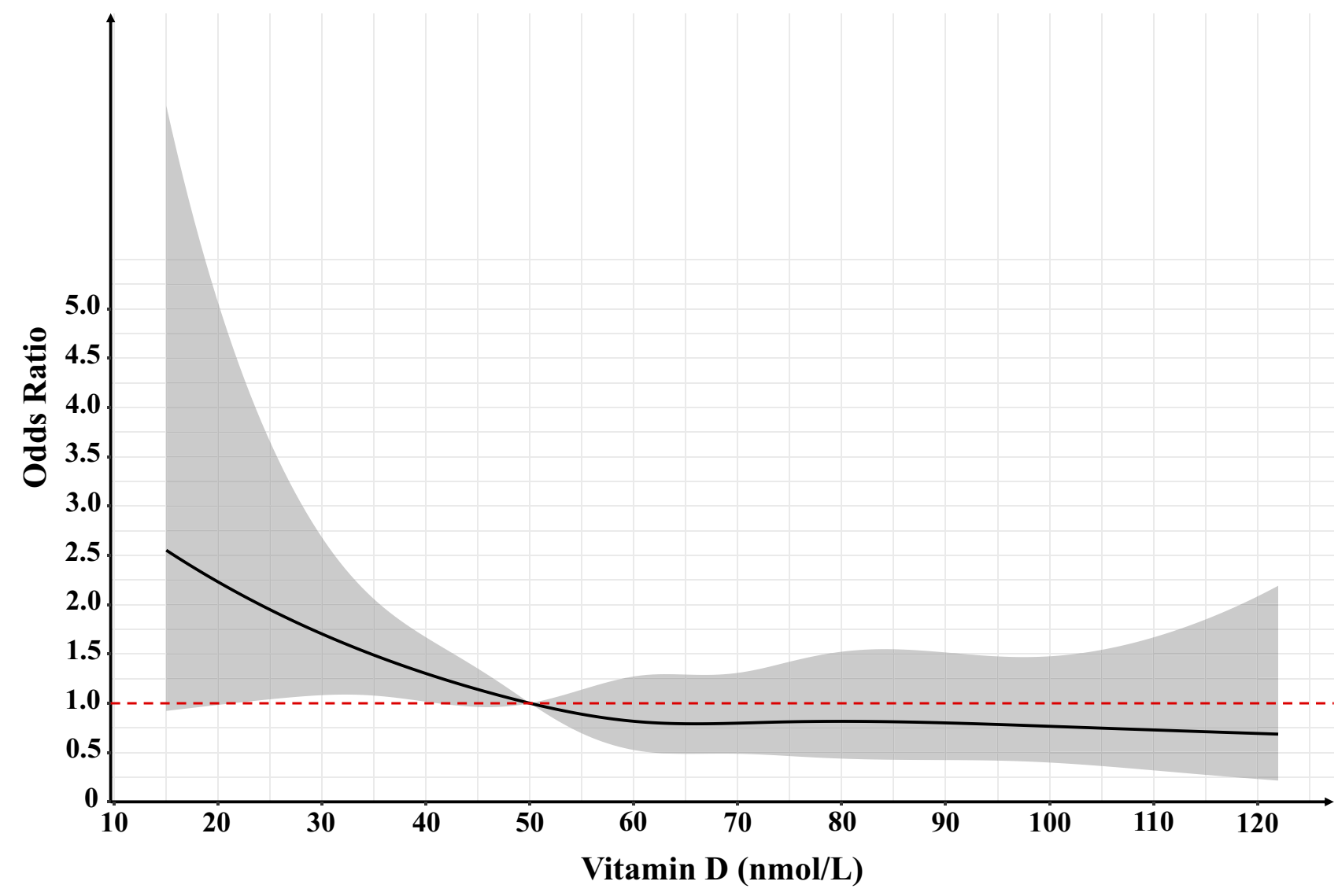

Figure 2 Association between vitamin D levels and risk of PSD. The reference vitamin D was $50 \mathrm{nmol} / \mathrm{L}$. The both edges of the gray area represent $95 \%$ confidence intervals. And the black solid curve is the ORs value. ORs and $95 \%$ confidence intervals derived from restricted cubic spline regression, adjusting for the same variables as model 3 in Table 3, with knots placed at the 5th, 35th, 65th, and 95th percentiles of the distribution of serum vitamin D.

alveolar inflammation, epithelial damage, and hypoxia. ${ }^{45}$ Other studies have proved that, in disease settings, vitamin $\mathrm{D}$ has positive effects on maintaining lung epithelial integrity and inhibiting inflammatory responses. ${ }^{46,47}$ Vitamin D supplementation ameliorated pulmonary morphological alternations in LPS-induced bronchopulmonary dysplasia, inhibited IFN- $\gamma$ overproduction and, thereby, suppressed inflammation. ${ }^{48}$ Vitamin D was also confirmed to enhance the ability of neutrophils to kill Streptococcus pneumoniae and inhibit excessive inflammation and apoptosis. ${ }^{49}$ Similar beneficial effects of vitamin D were observed in paraquat-induced lung fibrosis; vitamin $\mathrm{D}$ exhibited its anti-inflammatory effects by decreasing the secretion of pro-inflammatory cytokines. ${ }^{50} \mathrm{~A}$ study of male C57B16 mice concluded that supplemental vitamin D in advance can attenuate acute anti-inflammatory actions in the ischemia-reperfusion brain. ${ }^{51}$

Our research team also enrolled AIS patients form this retrospective clinical database between January 2018 and January 2019 to develop an easy-to-use nomogram model for predicting the risk of SAP in AIS patients. ${ }^{52}$ The nomogram contained predictors including age, NIHSS score on admission, atrial fibrillation, nasogastric tube intervention, mechanical ventilation, fibrinogen, and leukocyte count. Furthermore, the SAP nomogram showed good predictive performance in training cohort and validation cohort, and it was superior to other conventional models. However, we did not collect the data of vitamin D for analysis before, so vitamin D was not included in this nomogram model as a predictor. Although these two studies had 231 overlapped patients, the purposes and methods of these two studies were completely different. Therefore, we think that the potential overlap between the patients in these two studies does not affect the result of the study and the exploration of the clinical characteristics of SAP patients from different perspectives.

This study has several limitations. First, because it was a retrospective, single-center analysis, we cannot conclude a causal relationship between vitamin D levels and SAP. Additional large-scale, prospective clinical cohorts are 
needed to confirm our findings. Second, data on eating habits, nutrient intake, and parathyroid hormone levels were not available. All enrolled patients were elderly people from a single center and we assumed that there was no significant difference in their dietary habits. Third, serum vitamin D was measured only once on admission; further longitudinal studies are needed to evaluate the effects of dynamic changes in vitamin D levels after stroke on the outcome. Finally, our analysis did not consider certain drugs that can influence vitamin D levels.

\section{Conclusions}

In conclusion, our results indicate that low serum vitamin D on admission is associated with in-hospital SAP in patients with AIS. This study may provide insights for further clinical trials to examine whether vitamin D supplementation can prevent or reduce the burden of SAP after AIS.

\section{Abbreviations}

AIS, acute ischemic stroke; BUN, blood urea nitrogen; CI, confidence interval; COPD, Chronic obstructive pulmonary disease; DBP, diastolic blood pressure; GFR, glomerular filtration rate; HDL-C, high density lipoprotein cholesterol; LDL-C, low density lipoprotein cholesterol; NIHSS, National Institutes of Health Stroke Scale; OR, odds ratio; SAP, stroke-associated pneumonia; SBP, systolic blood pressure; $\mathrm{SCr}$, serum creatinine concentration.

\section{Data Sharing Statement}

The data supporting this study is available from the corresponding author for reasonable request.

\section{Acknowledgments}

We thank the study participants and the clinical staff at all participating hospitals for their support and contribution to this project.

\section{Funding}

This work was supported by the Projects of Provincial Natural Science Foundation of Zhejiang (No. LY19H09 0013), and the Wenzhou Municipal Sci-Tech Bureau Program (ZS2017011).

\section{Disclosure}

The authors declare that there are no conflicts of interest in this work.

\section{References}

1. Westendorp WF, Nederkoorn PJ, Vermeij JD, Dijkgraaf MG, van de Beek D. Post-stroke infection: a systematic review and meta-analysis. BMC Neurol. 2011;11:110. doi:10.1186/1471-2377-11-110

2. Smith CJ, Bray BD, Hoffman A, et al. Can a novel clinical risk score improve pneumonia prediction in acute stroke care? A UK multicenter cohort study. J Am Heart Assoc. 2015;4(1):e01307. doi:10.1161/JAHA.114.001307

3. Ji R, Shen H, Pan Y, et al. Novel risk score to predict pneumonia after acute ischemic stroke. Stroke. 2013;44(5):1303-1309. doi:10.1161/ STROKEAHA.111.000598

4. Finlayson O, Kapral M, Hall R, Asllani E, Selchen D, Saposnik G. Risk factors, inpatient care, and outcomes of pneumonia after ischemic stroke. Neurology. 2011;77(14):1338-1345. doi:10.1212/ WNL.0b013e31823152b1

5. Harms H, Grittner U, Droge H, Meisel A. Predicting post-stroke pneumonia: the PANTHERIS score. Acta Neurol Scand. 2013;128 (3):178-184. doi:10.1111/ane.2013.128.issue-3

6. Kammersgaard LP, Jorgensen HS, Reith J, et al. Early infection and prognosis after acute stroke: the copenhagen stroke study. J Stroke Cerebrovasc Dis. 2001;10(5):217-221. doi:10.1053/jscd.2001.30366

7. Ingeman A, Andersen G, Hundborg HH, Svendsen ML, Johnsen SP. In-hospital medical complications, length of stay, and mortality among stroke unit patients. Stroke. 2011;42(11):3214-3218. doi:10.1161/STROKEAHA.110.610881

8. Han B, Lyu Y, Sun H, Wei Y, He J. Low serum levels of vitamin D are associated with post-stroke depression. Eur J Neurol. 2015;22 (9):1269-1274.

9. Lim GB. Vitamin D supplementation and CVD. Nat Rev Cardiol. 2019;16:516. doi:10.1038/s41569-019-0238-6

10. Hausler D, Torke S, Peelen E, et al. High dose vitamin D exacerbates central nervous system autoimmunity by raising T-cell excitatory calcium. Brain. 2019;142:2737-2755. doi:10.1093/brain/awz190

11. Buell JS, Dawson-Hughes B. Vitamin D and neurocognitive dysfunction: preventing “D”ecline? Mol Aspects Med. 2008;29(6):415-422. doi:10.1016/j.mam.2008.05.001

12. Poole KE, Loveridge N, Barker PJ, et al. Reduced vitamin D in acute stroke. Stroke. 2006;37(1):243-245. doi:10.1161/01.STR.00001951 84.24297.c1

13. McGreevy C, Williams D. New insights about vitamin D and cardiovascular disease: a narrative review. Ann Intern Med. 2011;155 (12):820-826. doi:10.7326/0003-4819-155-12-201112200-00004

14. MacLaughlin J, Holick MF. Aging decreases the capacity of human skin to produce vitamin D3. J Clin Invest. 1985;76(4):1536-1538. doi:10.1172/JCI112134

15. Pilz S, Tomaschitz A, Drechsler C, Zittermann A, Dekker JM, Marz W. Vitamin D supplementation: a promising approach for the prevention and treatment of strokes. Curr Drug Targets. 2011;12 (1):88-96. doi:10.2174/138945011793591563

16. Takeda M, Yamashita T, Sasaki N, et al. Oral administration of an active form of vitamin D3 (calcitriol) decreases atherosclerosis in mice by inducing regulatory $\mathrm{T}$ cells and immature dendritic cells with tolerogenic functions. Arterioscler Thromb Vasc Biol. 2010;30 (12):2495-2503. doi:10.1161/ATVBAHA.110.215459

17. Arsava EM, Helenius J, Avery R, et al. Assessment of the predictive validity of etiologic stroke classification. JAMA Neurol. 2017;74 (4):419-426. doi:10.1001/jamaneurol.2016.5815

18. Ross AC, Manson JE, Abrams SA, et al. The 2011 dietary reference intakes for calcium and vitamin D: what dietetics practitioners need to know. J Am Diet Assoc. 2011;111(4):524-527. doi:10.1016/j. jada.2011.01.004

19. Chung PW, Park KY, Kim JM, et al. 25-hydroxyvitamin D status is associated with chronic cerebral small vessel disease. Stroke. 2015;46 (1):248-251. doi:10.1161/STROKEAHA.114.007706 
20. Garner JS, Jarvis WR, Emori TG, Horan TC, Hughes JM. CDC definitions for nosocomial infections, 1988. Am J Infect Control. 1988;16(3):128-140. doi:10.1016/0196-6553(88)90053-3

21. Smith CJ, Kishore AK, Vail A, et al. Diagnosis of stroke-associated pneumonia: recommendations from the pneumonia in stroke consensus group. Stroke. 2015;46(8):2335-2340. doi:10.1161/ STROKEAHA.115.009617

22. Durrleman S, Simon R. Flexible regression models with cubic splines. Stat Med. 1989;8(5):551-561. doi:10.1002/(ISSN)1097-0258

23. Rao SJ. Regression modeling strategies: with applications to linear models, logistic regression, and survival analysis. Pub Am Stat Assoc. 2005;98(461):257-258. doi:10.1198/jasa.2003.s263

24. Gong S, Zhou Z, Zhou M, et al. Validation of risk scoring models for predicting stroke-associated pneumonia in patients with ischaemic stroke. Stroke Vasc Neurol. 2016;1(3):122-126. doi:10.1136/svn2016-000025

25. Zapata-Arriaza E, Moniche F, Blanca PG, et al. External validation of the ISAN, A2DS2, and AIS-APS scores for predicting stroke-associated pneumonia. J Stroke Cerebrovasc Dis. 2018;27 (3):673-676. doi:10.1016/j.jstrokecerebrovasdis.2017.09.059

26. Nam KW, Kim TJ, Lee JS, et al. High Neutrophil-to-Lymphocyte Ratio Predicts Stroke-Associated Pneumonia. Stroke. 2018;49 (8):1886-1892. doi:10.1161/STROKEAHA.118.021228

27. Bruening T, Al-Khaled M. Stroke-associated pneumonia in thrombolyzed patients: incidence and outcome. J Stroke Cerebrovasc Dis. 2015;24 (8):1724-1729. doi:10.1016/j.jstrokecerebrovasdis.2015.03.045

28. Yuan MZ, Li F, Tian X, et al. Risk factors for lung infection in stroke patients: a meta-analysis of observational studies. Expert Rev Anti Infect Ther. 2015;13(10):1289-1298. doi:10.1586/14787210.2015.1085302

29. Kumar S, Doughty C, Doros G, et al. Recovery of swallowing after dysphagic stroke: an analysis of prognostic factors. J Stroke Cerebrovasc Dis. 2014;23(1):56-62. doi:10.1016/j. jstrokecerebrovasdis.2012.09.005

30. Flowers HL, Silver FL, Fang J, Rochon E, Martino R. The incidence, co-occurrence, and predictors of dysphagia, dysarthria, and aphasia after first-ever acute ischemic stroke. J Commun Disord. 2013;46 (3):238-248. doi:10.1016/j.jcomdis.2013.04.001

31. Okubo PC, Fabio SR, Domenis DR, Takayanagui OM. Using the National Institute of Health Stroke Scale to predict dysphagia in acute ischemic stroke. Cerebrovasc Dis. 2012;33(6):501-507. doi:10.1159/ 000336240

32. Martino R, Foley N, Bhogal S, Diamant N, Speechley M, Teasell R. Dysphagia after stroke: incidence, diagnosis, and pulmonary complications. Stroke. 2005;36(12):2756-2763. doi:10.1161/01. STR.0000190056.76543.eb

33. Hoffmann S, Harms H, Ulm L, et al. Stroke-induced immunodepression and dysphagia independently predict stroke-associated pneumonia - the predict study. J Cereb Blood Flow Metab. 2017;37 (12):3671-3682. doi:10.1177/0271678X16671964

34. Henke C, Foerch C, Lapa S. Early screening parameters for dysphagia in acute ischemic stroke. Cerebrovasc Dis. 2017;44(5-6):285290. doi:10.1159/000480123

35. Ishigami K, Okuro M, Koizumi Y, et al. Association of severe hypertension with pneumonia in elderly patients with acute ischemic stroke. Hypertens Res. 2012;35(6):648-653. doi:10.1038/hr.2012.7

36. Hug A, Murle B, Dalpke A, Zorn M, Liesz A, Veltkamp R. Usefulness of serum procalcitonin levels for the early diagnosis of stroke-associated respiratory tract infections. Neurocrit Care. 2011;14(3):416-422. doi:10.1007/s12028-009-9325-6
37. Wartenberg KE, Stoll A, Funk A, Meyer A, Schmidt JM, Berrouschot J. Infection after acute ischemic stroke: risk factors, biomarkers, and outcome. Stroke Res Treat. 2011;2011:830614. doi:10.4061/2011/830614

38. Ulm L, Hoffmann S, Nabavi D, et al. The randomized controlled STRAWINSKI trial: procalcitonin-guided antibiotic therapy after stroke. Front Neurol. 2017;8:153. doi:10.3389/fneur.2017.00153

39. Niimi M, Hashimoto G, Hara T, et al. Relationship between frequency of spontaneous swallowing and salivary substance p level in patients with acute stroke. Dysphagia. 2018;33(4):414-418. doi:10.1007/s00455-017-9867-2

40. Zapata-Arriaza E, Mancha F, Bustamante A, et al. Biomarkers predictive value for early diagnosis of stroke-associated pneumonia. Ann Clin Transl Neurol. 2019;6(9):1882-1887. doi:10.1002/acn3.50849

41. Anderson JL, May HT, Horne BD, et al. Relation of vitamin D deficiency to cardiovascular risk factors, disease status, and incident events in a general healthcare population. Am J Cardiol. 2010;106(7):963-968. doi:10.1016/j.amjcard.2010.05.027

42. Kiggundu DS, Mutebi E, Kibirige D, et al. Vitamin D deficiency and its characteristics among patients with acute stroke at a national referral hospital in Kampala Uganda. BMC Endocr Disord. 2015;15:53. doi:10.1186/s12902-015-0053-y

43. Jovanovich AJ, Ginde AA, Holmen J, et al. Vitamin D level and risk of community-acquired pneumonia and sepsis. Nutrients. 2014;6 (6):2196-2205. doi:10.3390/nu6062196

44. Rafiq R, Thijs W. Associations of serum 25(OH)D concentrations with lung function, airway inflammation and common cold in the general population. Nutrients. 2018;10(1):pii: E3040.

45. Dancer RC, Parekh D, Lax S, et al. Vitamin D deficiency contributes directly to the acute respiratory distress syndrome (ARDS). Thorax. 2015;70(7):617-624. doi:10.1136/thoraxjnl-2014-206680

46. Gorman S, Buckley AG, Ling KM, et al. Vitamin D supplementation of initially vitamin D-deficient mice diminishes lung inflammation with limited effects on pulmonary epithelial integrity. Physiol Rep. 2017;5:15. doi:10.14814/phy2.13371

47. Yao L, Shi Y, Zhao X, et al. Vitamin D attenuates hyperoxia-induced lung injury through downregulation of toll-like receptor 4. Int J Mol Med. 2017;39(6):1403-1408. doi:10.3892/ijmm.2017.2961

48. Liu C, Chen Z, Li W, Huang L, Zhang Y. Vitamin D enhances alveolar development in antenatal lipopolysaccharide-treated rats through the suppression of interferon-gamma production. Front Immunol. 2017;8:1923. doi:10.3389/fimmu.2017.01923

49. Subramanian K, Bergman P, Henriques-Normark B. Vitamin D promotes pneumococcal killing and modulates inflammatory responses in primary human neutrophils. J Innate Immun. 2017;9 (4):375-386. doi:10.1159/000455969

50. Schapochnik A, da Silva MR, Leal MP, et al. Vitamin D treatment abrogates the inflammatory response in paraquat-induced lung fibrosis. Toxicol Appl Pharmacol. 2018;355:60-67. doi:10.1016/j. taap.2018.06.020

51. Evans MA, Kim HA, Ling YH, et al. Vitamin D3 supplementation reduces subsequent brain injury and inflammation associated with ischemic stroke. Neuromolecular Med. 2018;20(1):147-159. doi:10.1007/s12017-018-8484-Z

52. Huang GQ, Lin YT, Wu YM, Cheng QQ, Cheng HR, Wang Z. Individualized prediction of stroke-associated pneumonia for patients with acute ischemic stroke. Clin Interv Aging. 2019;14:1951-1962. doi:10.2147/CIA.S225039 


\section{Publish your work in this journal}

Clinical Interventions in Aging is an international, peer-reviewed journal focusing on evidence-based reports on the value or lack thereof of treatments intended to prevent or delay the onset of maladaptive correlates of aging in human beings. This journal is indexed on PubMed Central, MedLine, CAS, Scopus and the Elsevier

Bibliographic databases. The manuscript management system is completely online and includes a very quick and fair peer-review system, which is all easy to use. Visit http://www.dovepress.com/ testimonials.php to read real quotes from published authors. 